\title{
Development of a Host-Induced RNAi System in the Wheat Stripe Rust Fungus Puccinia striiformis f. sp. tritici
}

\author{
Chuntao Yin, ${ }^{1}$ James E. Jurgenson, ${ }^{2}$ and Scot H. Hulbert ${ }^{1}$ \\ ${ }^{1}$ Department of Plant Pathology, Washington State University, Pullman, WA 99164-6430, U.S.A.; ${ }^{2}$ Department of Biology, \\ University of Northern lowa, Cedar Falls, IA 50614, U.S.A.
}

Submitted 5 October 2010. Accepted 20 December 2010.

\begin{abstract}
Rust fungi cause devastating diseases of wheat and other cereal species globally. Genetic resistance is the preferred method to control rusts but the effectiveness of race-specific resistance is typically transient due to the genetic plasticity of rust populations. The advent of RNA interference (RNAi) technology has shown promise for the engineering of resistance to some biotrophic pathogens in plants by altering the expression of essential pathogens' genes. Gene fragments from the rust fungi Puccinia striiformis f. sp. tritici or $P$. graminis f. sp. tritici were delivered to plant cells through the Barley stripe mosaic virus system, and some reduced the expression of the corresponding genes in the rust fungus. The ability to detect suppression was associated with the expression patterns of the fungal genes because reduction was only detected in transcripts with relatively high levels of expression in fungal haustoria. The results indicate that an in planta RNAi approach can be used in functional genomics research for rust fungi and that it could potentially be used to engineer durable resistance.
\end{abstract}

Rust fungi can cause devastating diseases of wheat and other cereal species that are the staple food sources in many areas of the world. Three Puccinia spp. attack wheat: Puccinia graminis f. sp. tritici, $P$. triticina, and $P$. striiformis f. sp. tritici cause stem rust, leaf rust, and stripe rust, respectively. The damage caused by each of these rusts has made the development of resistant cultivars a high priority for wheat-breeding programs around the world. Resistance breeding has been a constant effort due to the ability of these fungi to evolve new pathotypes to which the resistance is not effective. In the 1990s, wheat breeders and rust workers in the United States and most other parts of the world were more focused on finding sources of resistance to leaf rust and stripe rust because sources of resistance to stem rust had been effective for many years. This changed in 1999, when a new, highly virulent strain of $P$. graminis f. sp. tritici, Ug99 (race TTKSK), was identified in Uganda (Pretorius et al. 2000). This and subsequent virulent pathotypes have recently spread into other African countries and the Middle East (Nazari et al. 2009; Singh et al. 2008; Wanyera et al. 2006). Currently, approximately $80 \%$ of the wheat cultivars grown in the at-risk areas are susceptible to Ug99. Epidemics of these virulent strains could result in neartotal crop loss and are considered a major threat to world food

Corresponding author: S. H. Hulbert; Telephone: +1.509.335.3722; Fax: +1.509.335.9581; E-mail: scot_hulbert@wsu.edu security. The appearance of these new virulent strains to what had been, for decades, resistant cultivars illustrates the urgent need for development of truly durable rust resistance in cereals. Because most genetic resistance in cereals has not been durable, novel approaches for development of more long-lasting resistance to these highly variable fungal pathogens are desirable.

RNA interference (RNAi) is a cellular process that is shared by all eukaryotic organisms with apparent roles in gene regulation and defense against viral infection (Baulcombe 2004). RNAi is typically done by application or expression of a double-stranded RNA (dsRNA) homologous to a target sequence to silence expression of that sequence. RNAi technology has been used commercially to engineer virus resistance in plants by expression of viral sequences as transgenes (Frizzi and Huang 2010). The technology has also been used experimentally for functional genomics of insects and nematodes (Hannon 2002) and silencing has been demonstrated for several insects and nematodes by simply feeding the dsRNA of the target gene (Huvenne and Smagghe 2010). Engineering of host-induced RNAi by expressing dsRNA in plants has shown promise for both insect and nematode resistance. Viable levels of resistance to Heterodera schachtii, the sugar beet cyst nematode, were demonstrated in Arabidopsis by expressing dsRNA constructs of genes whose suppression interfered with the nematode life cycle (Huang et al. 2006; Sindhu et al. 2009; Yadav et al. 2006). Similar experiments expressing western corn rootworm RNAi in corn plants showed significant reductions in feeding damage (Baum et al. 2007). There also appears to be potential for host-induced silencing of parasitic weeds, such as Tryphysaria spp., which form invasive haustoria in host roots. Tomilov and associates (2008) were able to suppress $\beta$-glucuronidase (GUS) expression in Tryphysaria spp. by expressing dsRNA of the GUS gene in the host plant. Like other eukaryotes, fungi are sensitive to RNAi (Nakayashiki 2005; Nakayashiki and Nguyen 2008; Nakayashiki et al. 2006) and recent studies have demonstrated that expression of dsRNAs from Fusarium verticillioides or Blumeria graminis genes in planta can silence the expression of their respective genes in the infecting fungi (Nowara et al. 2010; Tinoco et al. 2010). Although neither of these pathogens are closely related to rust fungi, the rusts are similar to B. graminis and the other powdery mildews in their biotropic habit and formation of haustorial cells. These cells are separated from the host cytoplasm only by the host cell membrane and extrahaustorial matrix (Mendgen and Hahn 2002; Szabo and Bushnell 2001) and, if silencing signals generated in the host cell can cross this barrier, gene silencing may be triggered in haustorial cells and possibly interfere with pathogenicity or other metabolic processes. 
Virus-induced gene silencing (VIGS) uses viral vectors to produce dsRNA of a target gene fragment and trigger RNAi silencing (Becker and Lange 2009). It is a powerful reversegenetics tool that is particularly useful for species where stable transformants are difficult to construct. Although originally developed and used in model plants such as Nicotiana benthamiana (Kumagai et al. 1995), new protocols and viral vectors have expanded its utility to other species, including monocots (Holzberg et al. 2002; Renner et al. 2009; Scofield and Nelson 2009; Scofield et al. 2005; Wang et al. 2009). The Barley stripe mosaic virus (BSMV)-VIGS system has been used successfully by several groups to scrutinize candidate genes for their involvement in rust resistance in wheat (Cloutier et al. 2007; Scofield et al. 2005; Zhou et al. 2007). In this study, the BSMV-VIGS system is used to express dsRNA from Puccinia genes in plants to determine whether silencing signals can be delivered to the pathogen and suppress expression of the fungal genes. The ultimate goals are to develop a host-induced gene-silencing system for functional analysis of Puccinia genes and, possibly, methodology for developing rust-resistant cereals.

\section{RESULTS}

\section{Silencing expression of $\boldsymbol{P}$. striiformis $\mathbf{f}$. sp. tritici transcript} PSTha12J12 in wheat using BSMV as a VIGS vector.

In order to test whether rust genes can be silenced in planta, a $P$. striiformis f. sp. tritici gene expressed in haustoria
(PSTha12J12) was selected for analysis. PSTha12J12 was a haustorial cDNA coding for a predicted secreted protein that showed no significant homology to sequences in public databases, including the $P$. graminis genome database (Yin et al. 2009). The PSTha12J12 transcript was highly abundant in planta compared with urediniospores and also appeared more abundant in haustorial cells than in P. striiformis f. sp. triticiinfected leaves (Table 1). The RNAi target region was chosen to be rust-specific by homology searches to all wheat sequences in the database to avoid nonspecific silencing of plant genes. Total RNA was extracted from the leaves of 'Zak' wheat infected with BSMV carrying the RNAi target region of PSTha12J12 and P. striiformis f. sp. tritici race PST-78. RNA was also isolated from control seedlings which were infected with the BSMV::multicloning site (MCS) vector carrying no fungal sequences (Brueggeman et al. 2008) and PST-78. The level of PSTha12J12 expression was determined by comparative quantitative real-time polymerase chain reaction (qRTPCR) (Pfaffl 2001) using elongation factor-1 (PSTEF1) to normalize RNA amounts (Yin et al. 2009). In the first experiment, the level of PSTha12J12 expression in each of six individual silenced seedlings was compared with each of six control seedlings. Five of the six seedlings in the first experiment had significantly reduced expression. In the second experiment, three of five seedlings had significantly less expression than the six control plants. Between the two experiments, reduced PSTha12J12 expression was observed in eight of 11 seedlings tested, and these seedlings showed an average of $53 \%$ reduc-

Table 1. Expression of Puccinia striiformis f. sp. tritici or P. graminis f. sp. tritici genes in different developmental stages

\begin{tabular}{|c|c|c|c|c|}
\hline \multirow[b]{2}{*}{ Gene $^{a}$} & \multirow[b]{2}{*}{ Similarity (Blast X) (accession) } & \multicolumn{2}{|c|}{ Relative expression } & \multirow[b]{2}{*}{ Expression pattern } \\
\hline & & InfL/Ured $^{b}$ & Haust/InfL ${ }^{c}$ & \\
\hline PSTha12J12 & Unknown (GH737467) & $104.31 \pm 28.23$ & $747.76 \pm 10.29$ & High in Haust and InfL \\
\hline PSTha5A23 & Unknown (GH737046) & $3617.32 \pm 607.41$ & $27.90 \pm 2.99$ & High in Haust and InfL \\
\hline PSTha12H2 & Unknown (GH737173) & $23.48 \pm 3.10$ & $90.52 \pm 4.86$ & High in Haust and InfL \\
\hline PSTha2A5 & Predicted protein (GH737102) & $119.89 \pm 48.27$ & $91.73 \pm 4.69$ & High in Haust and InfL \\
\hline PSTha5A1 & Chitinase (GH737242) & $5980.69 \pm 867.12$ & $151.35 \pm 3.02$ & High in Haust and InfL \\
\hline PSTha12O3 & HXT1p hexose transporter (GH737482) & $0.16 \pm 0.01$ & $12.61 \pm 0.18$ & High in Haust and Ured \\
\hline PSTha9F18 & Hypothetical protein (GH737274) & $0.0011 \pm 0.0003$ & $418.98 \pm 39.31$ & High in Haust and Ured \\
\hline PST58H22a & $\beta$-tubulin (EG374306) & $0.93 \pm 0.05$ & $1.04 \pm 0.01$ & Constitutive \\
\hline PSTGAPDH & GAPDH (GR303771) & $4.41 \pm 1.17$ & $1.20 \pm 0.08$ & Constitutive \\
\hline PSTActin & Actin (ES321956) & $0.22 \pm 0.01$ & $2.47 \pm 0.26$ & Constitutive \\
\hline PGTEPSPS & EPSPS (PGTG_13928) & $0.24 \pm 0.02$ & $2.78 \pm 0.45$ & Constitutive \\
\hline
\end{tabular}

${ }^{a}$ Gene designations beginning with PST are from $P$. striiformis f. sp. tritici and PGTEPSPS is from $P$. graminis f. sp. tritici. PSTEF1 was used to normalize RNA amounts for $P$. striiformis $\mathrm{f}$. sp. tritici gene assays and PGTActin for PGTEPSPS gene assays.

${ }^{\mathrm{b}}$ Ratio of expression in infected leaves (InfL) versus expression in urediniospores (Ured).

${ }^{c}$ Ratio of expression in haustoria (Haust) versus expression in infected leaves (InfL).

Table 2. Real-time polymerase chain reaction analysis of rust gene expression in wheat or barley leaves inoculated with Barley stripe mosaic virus constructs

\begin{tabular}{|c|c|c|c|}
\hline Gene $^{a}$ & $\begin{array}{l}\text { No. of silenced plants/total no. of } \\
\text { tested plants }\end{array}$ & $\begin{array}{l}\text { Average relative gene expression in } \\
\text { silenced plants }\end{array}$ & $\begin{array}{c}\text { Expression differences between } \\
\text { control plants }\end{array}$ \\
\hline PSTha12J12 & $5 / 6,3 / 5$ & $0.47 \pm 0.17$ & $1.17 \pm 0.49$ \\
\hline PSTha5A23 & $5 / 6$ & $0.48 \pm 0.20$ & $1.02 \pm 0.37$ \\
\hline PSTha $12 \mathrm{H} 2$ & $2 / 4,2 / 6$ & $0.64 \pm 0.11$ & $1.20 \pm 0.24$ \\
\hline PSTha2A5 & $1 / 6,2 / 5,0 / 6$ & $0.44 \pm 0.18$ & $1.73 \pm 2.54$ \\
\hline PSTha5A1 & $2 / 6,5 / 6$ & $0.55 \pm 0.16$ & $1.15 \pm 0.28$ \\
\hline PSTha $12 \mathrm{O} 3$ & $6 / 6,6 / 6$ & $0.30 \pm 0.22$ & $1.24 \pm 0.46$ \\
\hline PSTha9F18 & $2 / 6,1 / 6$ & $0.48 \pm 0.31$ & $1.50 \pm 1.75$ \\
\hline PST58H22a ( $\beta$-tubulin) & $0 / 6,2 / 6$ & $0.80 \pm 0.12$ & $1.11 \pm 0.37$ \\
\hline PSTGAPDH & $0 / 6$ & $\ldots$ & $1.19 \pm 0.35$ \\
\hline PSTActin & $0 / 6$ & $\ldots$ & $1.06 \pm 0.29$ \\
\hline PSTEF1 & $1 / 6$ & $0.80 \pm 0.08$ & $1.10 \pm 0.11$ \\
\hline PGTEPSPS & $0 / 6$ & $\ldots$ & $1.00 \pm 0.13$ \\
\hline
\end{tabular}

\footnotetext{
${ }^{a}$ Gene designations beginning with PST are from P. striiformis f. sp. tritici and PGTEPSPS is from P. graminis f. sp. tritici.

b Values separated by commas represent separate experiments.

c Average and standard deviation of the ratio of gene expression in all silenced plants.

d Average and standard deviation of the fold difference in gene expression between all possible pairs of control plants. Each fold calculation is the higherexpressing plant/low-expressing plant, so that values are all 1.0 (if identical) or greater.
} 
tion in expression level (Table 2). The results indicated that PSTha12J12 transcript can be suppressed in planta through BSMV-VIGS.

\section{Optimization of conditions for VIGS of Puccinia genes.}

In initial experiments, 10-day-old wheat seedlings were inoculated with the BSMV constructs, which resulted in nearly $100 \%$ infection of the leaves as determined by virus symptoms. However, the development of viral symptoms was variable among the leaves, and this may have contributed to the variability in the fungal transcript suppression. The BSMV construct carrying the PSTha12J12 fragment was used to determine whether the period between virus and rust inoculations was important for VIGS efficiency. Rust inoculations were performed at three timepoints $(10,15$, and 20 days) after virus infection. The PSTha12J12 transcript abundance was assessed by qRT-PCR from the infected wheat leaves 7 days after stripe rust inoculation. Five of six seedlings infected with $P$. striiformis f. sp. tritici race PST-78 10 days after recombinant virus inoculation had significantly reduced expression. On average, these five seedlings exhibited a $66 \%$ reduction of PSTha12J12 expression compared with the control plants (Table 3). A trend toward reduced expression was also observed in the seedlings that were rust inoculated 15 and 20 days after virus infection; however the level of silencing was slightly lower for the 15day timepoint and fewer seedlings showed significant reductions for the 20-day timepoint. Therefore, it was apparent that silencing could be induced in rust-inoculated seedlings at a range of times after VIGS inoculation, and 10 days after inoculation was sufficient. Under the growth conditions used, 10 days was sufficient for new seedling leaves to emerge following the VIGS infection of the youngest seedling leaves and also allowed initiation of viral symptoms so that infected seedling leaves can be selected.

\section{Identification of target genes with different expression patterns.}

To determine whether additional rust genes could be silenced in planta with BSMV-VIGS, more rust genes were selected for silencing. Genes were selected with a variety of expression patterns so that the possible effects of fungal tissue or developmental stage could be examined. Four sequences (PSTha5A23, PSTha12H2, PSTha2A5, and PSTha5A1) isolated from a $P$. striiformis $\mathrm{f}$. sp. tritici haustorial cDNA library were found to have expression patterns similar to PSTha12J12 (Table 1), in that they had higher transcript levels in purified haustorial cells than $P$. striiformis f. sp. tritici-infected leaves or urediniospores. Three of these genes (PSTha5A23, PSTha12H2, and PSTha2A5) were predicted to code for secreted proteins that did not show significant homology to protein sequences in public databases (Yin et al. 2009). The other gene, PSTha5A1, was predicted to code for a chitinase protein and showed homology to a family of genes in the stem rust fungus $P$. graminis $\mathrm{f}$. sp. tritici. The sequence targeted for silencing this gene was homologous to those that were relatively conserved among the $P$. graminis f. sp. tritici gene family but were diver-

Table 3. Real-time polymerase chain reaction analysis of suppression of PSTha12J12 expression in wheat leaves inoculated with Barley stripe mosaic virus:: PSTha12J12

\begin{tabular}{lcc}
\hline $\begin{array}{l}\text { Days between virus } \\
\text { and rust inoculations }\end{array}$ & $\begin{array}{c}\text { No. of silenced } \\
\text { plants/total no. of } \\
\text { tested plants }\end{array}$ & $\begin{array}{c}\text { Average relative } \\
\text { gene expression in } \\
\text { silenced plants }\end{array}$ \\
\hline 10 & $5 / 6$ & $0.34 \pm 0.17$ \\
15 & $5 / 6$ & $0.57 \pm 0.17$ \\
20 & $2 / 6$ & $0.60 \pm 0.27$ \\
\hline
\end{tabular}

gent from plant sequences to avoid unintended silencing of wheat chitinase genes. Two additional sequences (PSTha12O3 and PSTha9F18) were identified that had higher expression levels in purified haustorial cells than $P$. striiformis f. $\mathrm{sp}$. tritici-infected leaves but had relatively high expression in urediniospores. PSTha9F18 was predicted to encode for an unknown secreted protein and was estimated to have almost 1,000 -fold more transcripts in urediniospores than infected leaves (Table 1). PSTha12O3 was homologous to Uromyces fabae hexose transporters (Voegele et al. 2001). Although the copy numbers of these two genes are not known in the P. striiformis genome due to the lack of sequence availability, the PSTha9F18 gene was homologous to a single gene in the available $P$. graminis genome sequences while PSTha12O3 had two very similar homologs.

Four other $P$. striiformis f. sp. tritici genes were selected to represent genes that are expressed at similar levels in all cell types. One was an elongation factor-1 (PSTEF1) homolog that had been found previously to have uniform expression in different rust tissues (Yin et al. 2009). The second (PST58H22a) was predicted to code for $\beta$-tubulin and was found to be nearly uniform in transcript levels in haustorial cells, P. striiformis f. sp. tritici-infected leaves, and urediniospores (Table 1). The other two sequences were homologous to glyceraldehyde 3phosphate dehydrogenase (PSTGAPDH) and actin-encoding genes (PSTActin), respectively. Their expression patterns showed more fluctuation in different cell types but generally less than threefold differences between haustoria and infected leaves (Table 1). The copy number of these genes in the $P$. striiformis f. sp. tritici genome is not known but searches of the $P$. graminis genome sequence indicated they were probably single copy; only a single sequence was present for the EF1-encoding gene and duplicate, nearly identical sequences were present for the other three genes, probably representing different alleles at single loci. The last sequence was selected from P. graminis f. sp. tritici, the stem rust fungus, and was predicted to code for 5-enolpyruvylshikimate-3-phosphate synthase (PGTEPSPS). The sequence was available in the $P$. graminis $\mathrm{f}$. sp. tritici but not $P$. striiformis f. sp. tritici database sequences. The sequence was one of four homologous sequences in the $P$. graminis f. sp. tritici database with more than $80 \%$ nucleotide sequence identity. The EPSPS enzyme is essential for the synthesis of aromatic amino acids in plants, fungi, and bacteria. The broad-spectrum herbicide glyphosate inhibits this enzyme and rust fungal enzymes are also thought to be sensitive (Feng et al. 2005). Its transcripts were fourfold more abundant in urediniospores and twofold more in haustorial cells compared with total fungal cells in $P$. graminis f. sp. tritici infected leaves (Table 1).

\section{Detection of silencing is dependent on gene expression patterns.}

The transcript abundance of 10 additional targeted genes was analyzed by qRT-PCR in VIGS assays as described above for the PSTha12J12 gene. Significant silencing was detected for all six of the genes selected for higher levels of expression in haustorial cells than in total cells in infected wheat leaves, although it was barely noticeable for some of the genes (Table 2). The most extensive silencing was detected with the PSTha12O3 gene, in which significant reductions in gene expression were detected in all seedlings examined. In addition, the average level of gene expression was only $30 \%$ that of the control seedlings. Estimates of the level of gene expression in individual seedlings were as low as $10 \%$ for one of the PSTha12O3 seedlings. Most seedlings infected with VIGS constructs for the PSTha5A23 (five of six) and PSTha5A1 (seven of 12) transcripts also showed reductions in expression 
of the fungal genes, and the average levels of expression in silenced plants were approximately $50 \%$ of the controls. The least consistent silencing was observed for the PSTha2A5 and PSTha9F18 genes, for which significant reductions in transcript levels were observed for three of 17 and three of 12 seedlings, respectively.

To examine why the silencing results were so variable for the PSTha2A5 and PSTha9F18 genes, the variations in transcript levels among control seedlings were examined. The control seedlings were those infected with the BSMV::MCS that does not carry any fungal sequences; these seedlings have virus and rust symptoms similar to those infected with the silencing constructs. The variations among the control leaves were fairly low for most genes, ranging from nearly identical to approximately twofold differences. Transcript levels were more variable for the PSTha2A5 and PSTha9F18 genes (Table 2 ); individual seedling varied by as much as 15 - and ninefold, respectively. It is not clear what caused the variation in expression levels of these genes among the different seedlings.

The four genes chosen for their nearly constitutive expression, coding for $\beta$-tubulin, GAPDH, actin, and EF1, were consistently expressed in the control seedlings, as expected. When transcript levels of these genes were compared between seedlings infected with the silencing and control constructs, few differences were observed. Two of the seedlings infected with the PST58H22a construct and one with the PSTEF1 construct showed reductions but transcript levels were only reduced by approximately $20 \%$ of the control seedlings. No evidence of silencing was observed for the other two genes (Table 2).

A similar result was observed for the EPSPS-encoding gene from $P$. graminis f. sp. tritici. This gene had somewhat consistent expression between the different fungal cell types tested, with levels in haustorial cells estimated at only two to three times that of $P$. graminis f. sp. tritici-infected leaves (Table 1). Like the consistently expressed $P$. striiformis f. sp. tritici genes, no evidence of silencing was observed in leaves infected with the BSMV::PGTEPSPS and P. graminis f. $\mathrm{sp}$. tritici (Table 2).

\section{Rust disease assays.}

Plant leaves infected with various BSMV gene constructs, and even BSMV::MCS control constructs with no fungal genes, occasionally sporulated poorly after rust infection. To determine whether rust sporulation was correlated with the extent of viral symptoms on individual leaves, the viral symptoms before rust inoculation and subsequent rust sporulation were recorded. The extent of virus symptoms on individual leaves infected with the BSMV::MCS control appeared to have a small and inconsistent effect on the extent of rust sporulation $(P=0.195)$, with those showing the most severe symptoms sometimes showing slightly less rust sporulation. Poorly sporulating leaves could typically be avoided by not using leaves with severe viral symptoms when inoculating with rust (Fig. 1). The correlation between viral symptoms and rust sporulation on leaves infected with other gene constructs was similar to the control construct (data not shown) but none of them had statistically significant effects. Obvious reductions in rust development or sporulation were not observed for any of the genes tested in this study. Detection of whether any of the constructs could provide quantitative reductions in disease would require more extensive testing.

\section{DISCUSSION}

VIGS assays with $P$. striiformis $\mathrm{f}$. sp. tritici genes that are expressed in haustoria indicated that RNAi expressed in plant cells could silence rust genes of cereal rust pathogens. The extent of silencing detected appeared dependent on the expression patterns of the gene. Assays to determine whether silencing was occurring in individual seedlings were based on total RNA from infected leaves because purification of sufficient quantities of haustoria from small amounts of leaf tissue was not feasible. If only haustorial cells were receiving the silencing signal and silencing was not occurring throughout the fungal mycelia in the leaf, reductions in the amount of transcripts might not be apparent in genes expressed equally in all fungal cells in the leaves. A common feature of the genes for which silencing was observed was that they were expressed more highly in haustoria than they were in bulk fungal cells in the leaves. In contrast, no obvious silencing was apparent for any of the five genes analyzed whose expression was more constitutive, although the transcripts in one or two seedlings for PSTEF1 or PST58H22a showed small reductions. The simplest explanation is that silencing only occurs in cells near or in direct contact with the host cell cytoplasm. Silencing of four of seven differentially expressed genes was relatively efficient for VIGS, with expression being reduced approximately twoto tenfold in some seedling leaves, similar to what has been observed with host gene silencing (Scofield et al. 2005). Silencing of two of the other genes was extremely variable. The expression of these two genes was also highly variable in the control leaves, which were infected with the BSMV virus without fungal genes. It is not clear what caused their variable expression but such genes are poor candidates for silencing experiments.

The Puccinia spp. that cause rusts are obligately biotrophic basidiomycete fungi that grow as intercellular hyphae after entering stomata and form haustoria to derive nutrients and interact with host cells (Mendgen and Hahn 2002; Szabo and Bushnell 2001). In compatible interactions, these haustoriahost cell interactions remain alive and active for weeks, providing plenty of time for dsRNA fragments to have an effect if they can enter the haustorial cells. Nutrients acquired by the haustorial cells are presumably transferred to the haustorial mother cells and on to other mycelia cells through a thin haustorial neck. If the silencing signals do not extend into these other cell types, it affects the utility of silencing for functional
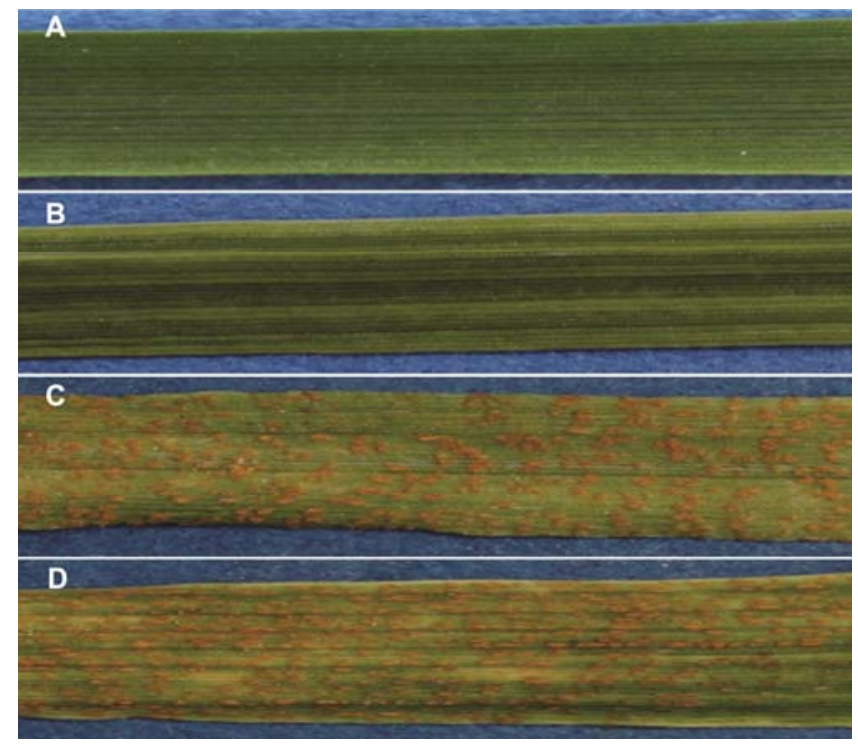

Fig. 1. Phenotypes of 'Zak' wheat inoculated with the virus vector (Barley stripe mosaic virus::multicloning site [BSMV::MCS]) and stripe rust PST78. A, Uninoculated leaf. B, BSMV::MCS-inoculated leaf, 10 days postinoculation (dpi). C, PST-78-inoculated leaf, 20 dpi. D, BSMV::MCS-inoculated, then PST-78-inoculated leaf, 20 dpi. 
genomics and strategies for engineering resistance. Genes that are specific to haustoria can be silenced and, if a reduction in transcript has an effect on its function, it may be possible to observe a phenotype, especially if its function is essential. Obvious reductions in rust development or sporulation were not observed for any of the genes tested. However, the genes selected for which silencing was observed were probably not the best choices for essential genes because they were selected for their expression patterns. Five of the seven genes selected for high haustorial expression were predicted to be effectorlike proteins, another was a member of a large and diverse chitinase gene family, and the seventh was a predicted sugar transporter. It is also possible that the function of all of these can be compensated for by other genes. With genes that are expressed in other cells as well as haustoria, silencing of genes in the haustorial cells only may not affect the fungus if the neighboring cells can provide either the protein or the metabolic product to the haustorial cell. For example, the EPSPS enzyme is required for aromatic amino acids, and inhibition affects rust fungi. If these amino acids can be supplied to haustoria from neighboring fungal cells, reductions in levels of the protein only in haustoria would not be effective. If silencing can only be achieved in haustorial cells, identification of essential genes that are expressed only in haustoria might be the best way to identify genes with phenotypes detrimental to fungal metabolism.

Successful VIGS depends upon a dynamic interplay between virus spread and plant growth. In previous studies with the temporal and spatial patterns of gene silencing in wheat and barley leaves, significant silencing was detected 3 days postinoculation and persisted until at least 21 days postinoculation (Hein et al. 2005; Scofield and Nelson 2009; Scofield et al. 2005). The present study also found that 10 days after virus infection was an adequate period to wait before inoculating with rust to get gene silencing. This provided sufficient time for selection of new, undamaged leaves with viral symptoms for rust resistance assays and allowed for rapid assays on seedling tissues, with little interference from adult-plant resistance

Table 4. Primers used in construction of Barley stripe mosaic virus-derived vectors and quantitative real-time polymerase chain reaction analysis to determine gene expression

\begin{tabular}{|c|c|c|}
\hline Primers & Sequence $\left(5^{\prime}\right.$ to $\left.3^{\prime}\right)$ & Size (bp) \\
\hline PSTha12H2F & ATGCGGCCGCTACGCTTCGAATCTTCTGTTCG & 156 \\
\hline PSTha12H2R & CCTTAATTAAGGTAGATTCTGCCTCCGTGACAA & $\ldots$ \\
\hline PSTha5A23F & TTATGCGGCCGCTACTGCCAACCGGTAGTTCATT & 191 \\
\hline PSTha5A23R & CCTTAATTAATGGCTGATGGTATTGGAACA & $\ldots$ \\
\hline PSTha5A1F & ATAAGAATGCGGCCGCTAAACTATTTTGATGACAAGCCTGGCACAG & 165 \\
\hline PSTha5A1R & CCTTAATTAAGGGAGGAATGGCTCTCCAGAACAC & $\ldots$ \\
\hline PSTha12J12F & ATAAGAATGCGGCCGCTAAACTATCTAAGACAGGGGCATTTCTTGA & 153 \\
\hline PSTha12J12R & CCTTAATTAAGGCATTTGGTGATGTTGGTATAGCAA & $\ldots$ \\
\hline PSTha2A5F & ATGCGGCCGCTATTCATCGTATTCGCAGTGTTG & 172 \\
\hline PSTha2A5R & ССTTAATTAAGGTACCTTCCACATGGTGAACTCC & $\ldots$ \\
\hline PSTTubulinF & ATAAGAATGCGGCCGCTAAACTAT TCCAGCTTGAGAGAATCAGCGTGT & 148 \\
\hline PSTTubulinR & CCTTAATTAAGGACAAAGTTGTCGGGACGGAAGAGA & $\ldots$ \\
\hline PSTha9F18F & ATAAGAATGCGGCCGCTAAACTAT TCAACAACCAGATGTCCACCCTGA & 164 \\
\hline PSTha9F18R & CCTTAATTAAGGGAAACCGCCGAAGTTGTTGGTGAT & $\ldots$ \\
\hline PSTEF1F & ATAAGAATGCGGCCGCTAAACTATTGGTCCGAACAACGATACGAGGAA & 323 \\
\hline PSTEF1R & CCTTAATTAAGGACCGTACCGATAACACCCGATCTT & $\ldots$ \\
\hline PSTha12O3F & ATAAGAATGCGGCCGCTAAACTAT GCCTGATCCCACACCCCATTCA & 181 \\
\hline PSTha12O3R & CCTTAATTAAGGTAACATTGACTGTTTGGTCCCCGC & $\ldots$ \\
\hline PSTActinF & ATAAGAATGCGGCCGCTAAACTAT TGACTGAAGCTCСТCTCAATCCCA & 209 \\
\hline PSTActinR & CСTTAATTAAGG CGCATGAGGTAGAGCGTAACCTTT & $\ldots$ \\
\hline PSTGAPDHF & ATAAGAATGCGGCCGCTAAACTAT AACTGGTGTCTTCACCACCAAGGA & 373 \\
\hline PSTGAPDHR & CCTTAATTAAGG AGGGATAACTTTGCCGACAGCCTT & $\ldots$ \\
\hline PGTEPSPSF & ATAAGAATGCGGCCGCTA AACTATTCCAGCTACTGGGCTTCCTTCAAA & 197 \\
\hline PGTEPSPSR & CCT TAA TTA AGGCC TTC TTG GCA AAT TGAGCG TCG & $\ldots$ \\
\hline RT-PSTha12H2F & ACGTCAGTCAAAGATGTCGGCGAA & 120 \\
\hline RT-PSTha12H2R & TTCCTATCAATTAGCGCGGGAGCA & $\ldots$ \\
\hline RT-PSTha5A23F & TTCCTACTCTGGCGACCAACATCA & 194 \\
\hline RT-PSTha5A23R & AAATCCGACTGACCGACATCCGTT & $\ldots$ \\
\hline RT-PSTha5A1F & ACCGTATCGAAAGTGGTGTACGCT & 82 \\
\hline RT-PSTha5A1R & TGTCGTCCATTGGTCCCATAGTGT & $\ldots$ \\
\hline RT-PSTha12J12F & GCTTCGTTCGGGATTCAAAGCAAC & 138 \\
\hline RT-PSTha12J12R & ACATCTTGGGAACAGGCAGTTTCG & $\ldots$ \\
\hline RT-PSTEF1F & TTCGCCGTCCGTGATATGAGACAA & 159 \\
\hline RT-PSTEF1R & ATGCGTATCATGGTGGTGGAGTGA & $\ldots$ \\
\hline RT-PSTha2A5F & TGAATGGGTCGGTTGCCACAGATA & 180 \\
\hline RT-PSTha2A5R & GGCCCAAAGGGAATGGTCGAATTT & $\ldots$ \\
\hline RT-PSTTubulinF & CCGATCAATTCACGGCCATGTTCA & 174 \\
\hline RT-PSTTubulinR & AАСССТCTTCAACTTCCTCGTCGT & $\ldots$ \\
\hline RT-PSTha9F18F & ATTCGAGATTAACGCGACCAACGG & 169 \\
\hline RT-PSTha9F18R & GAAAGGTCAATGACAACGGCGTCT & $\ldots$ \\
\hline RT-PSTha12O3F & GCATGCTGTGGCTTGTGCTTCTTA & 173 \\
\hline RT-PSTha12O3R & AGTGGCGTGGTTGCATGATGAGTA & $\ldots$ \\
\hline RT-PSTActinSF & CCGCCTTGGTTCTTGACAATGGTT & 98 \\
\hline RT-PSTActinSR & AGGACGACCACAGATCGAAGGAAA & $\ldots$ \\
\hline RT-PSTGAPDHF & GTTGGAATCAACGGCTTTGGTCGT & 159 \\
\hline RT-PSTGAPDHR & ACCTTTGAATCGACCGTGAGTGGA & $\ldots$ \\
\hline RT-PGTActinGF & TGTCGGGTGGAACGACCATGTATT & 146 \\
\hline RT-PGTActinGR & AGCCAAGATAGAACCACCGATCCA & $\ldots$ \\
\hline RT-PGTEPSPSF & TGGCCGAATTAGGCAAGATGGGTA & 111 \\
\hline RT-PGTEPSPSR & TGATACGGACTTGATCGCCACGTT & $\ldots$ \\
\hline
\end{tabular}


effects. Viral infection can affect rust symptoms in some inoculations but the effect is small.

In conclusion, our results suggested that some $P$. striiformis f. sp. tritici genes can be silenced through a host-induced RNAi system. The VIGS system could be a powerful reversegenetics tool for analyses of gene function in rust fungi, although it may not be able to silence all genes or silence genes in all tissues. If silencing is limited to haustorial cells, this will limit the genes that can be examined for function and will be an important consideration in designing constructs for engineering RNAi mediated defenses.

\section{MATERIALS AND METHODS}

\section{Plant materials, growth conditions, and fungal races.}

The plants used in this study included the Zak wheat and 'Steptoe' barley. Zak was used for all stripe rust ( $P$. striiformis f. sp. tritici) gene-silencing experiments and Steptoe was used for stem rust ( $P$. graminis f. sp. tritici) gene-silencing assays. Seedlings for VIGS assays were sown in pots containing potting mix and placed in growth chambers with temperatures of $24^{\circ} \mathrm{C}$ during the day and $20^{\circ} \mathrm{C}$ at night, 23 to $50 \%$ relative humidity, and $16 \mathrm{~h}$ of light. Plants were watered daily and fertilized with a dilute nutrient solution weekly. Urediniospores from $P$. striiformis f. sp. tritici (race PST-78) were increased on a wheat genotype (AvSYr8NIL) carrying the $Y r 8$ resistance gene in the 'Avocet Susceptible' background using the method as described by Chen and Line (1992) and urediniospores from $P$. graminis f. sp. tritici ( $P$. graminis f. sp. tritici MCC) were increased on Steptoe. Fresh spores were collected and used in inoculation experiments or stored at $-80^{\circ} \mathrm{C}$ for RNA extraction.

\section{Construction of BSMV-derived vectors.}

The three BSMV component vectors ( $\mathrm{p} \alpha, \mathrm{p} \beta \Delta \beta \mathrm{a}$, and $\mathrm{p} \gamma$ ) were used for gene silencing as described (Holzberg et al. 2002). P. striiformis f. sp. tritici genes targeted for silencing included seven sequences (PSTha12J12, PSTha5A23, PSTha12H2, PSTha2A5, PSTha5A1, PSTha12O3, and PSTha9F18) previously isolated from a cDNA library made from purified $P$. striiformis f. sp. tritici haustorial cells (Yin et al. 2009), four housekeeping genes (coding for EF1, $\beta$-tubulin, GAPDH, and actin), and one $P$. graminis f. sp. tritici gene coding for the EPSPS enzyme. Sequences targeted were used to search public sequence databases to avoid homology with plant sequences; none of the sequences used contained stretches of sequence identity longer than 23 nucleotides to any cereal expressed sequence tags or other sequences in public databases. Selected gene fragments were amplified by PCR from cDNA using primers listed in Table 4. Following digestion with restriction enzymes corresponding to Not I and PacI sites included in the primers, the amplicons were directionally ligated into NotI/PacI sites of the BSMV gamma vector. All constructs were verified by DNA sequencing at the Washington State University sequencing facility. The resulting viral genome included the antisense strand of the fungal transcript. The negative control (BSMV::MCS) carried only a 121-bp antisense fragment of the MCS from pBluescript $\mathrm{K} / \mathrm{S}$ and carried no Puccinia spp. sequences (Brueggeman et al. 2008).

\section{In vitro transcription of viral RNAs, virus inoculations, rust inoculations, and disease assays.}

To produce transcripts of viral RNAs in vitro, plasmids coding for the tripartite BSMV genome, $\mathrm{p} \alpha, \mathrm{p} \beta \Delta \beta \mathrm{a}$, and $\mathrm{p} \gamma$ (or recombinant p $\gamma$ plasmids), were linearized by MluI, SpeI, or BssHII digestion, respectively. In vitro transcripts were prepared from the three linearized plasmids using the mMessage mMachine T7 in vitro transcription kit (Ambion, Austin, TX, U.S.A.) following the manufacturer's instructions. Plants were infected with BSMV using the following protocol. Equal amounts $(2.5 \mu \mathrm{l})$ of each of the in vitro transcription reactions from the three viral RNAs were combined and added to $45 \mu \mathrm{l}$ of FES buffer ( $77 \mathrm{mM}$ glycine, $60 \mathrm{mM} \mathrm{K} \mathrm{HPO}_{4}, 22 \mathrm{mM} \mathrm{Na} \mathrm{P}_{2} \mathrm{O}_{7} \cdot 10 \mathrm{H}_{2} \mathrm{O}, 1 \%$ [wt/vol] bentonite, and $1 \%$ [wt/vol] celite). These mixtures were applied to wheat seedlings (10 to 12 days old, first and second fully expanded leaves) by rub inoculation. Seedlings were then lightly misted with water and returned to the growth chamber. After approximately 10 days, plants inoculated with virus or viral constructs developed virus symptoms. Leaf sections (tip, middle, and base) were rated for virus severity based on a 0 -to- 3 scale $(0=$ no symptoms, $1=$ very pale yellow stripes on leaf, $2=$ pale yellow stripes on leaf, and $3=$ pronounced yellow stripes on leaf). The infected wheat leaves, typically the third and fourth leaves, were then inoculated with $P$. striiformis $\mathrm{f}$. sp. tritici race PST78 as described by Chen and Line (1992). Seven days after inoculation with rust, the infected regions of the leaves were harvested and RNA was extracted for qRT-PCR analysis. Other infected plants were kept in the growth chamber for observations on the extent of stripe rust development at 20 days after inoculation based on the 0-to-9 scale (Line and Qayoum 1992). The virus-infected barley leaves were inoculated with $P$. graminis f. sp. tritici MCC of $P$. graminis f. sp. tritici as previously described (Horvath et al 2003). Five days after inoculation with $P$. graminis f. sp. tritici, the infected leaves were harvested for RNA extraction. Other infected plants were kept in the growth chamber until 12 days after inoculation, and the infection types were assessed based on a 0-to-4 rating scale (Stakman et al. 1962).

\section{RNA extraction and cDNA synthesis.}

$P$. striiformis f. sp. tritici and $P$. graminis f. sp. tritici haustoria were isolated from heavily rust infected leaves using ConA affinity chromatography as described previously (Yin et al. 2009). Total RNA was extracted from frozen powder using the Qiagen Plant RNeasy kit (Qiagen, Chatsworth, GA, U.S.A.) according to the manufacturer's instructions. All RNA samples were digested with DNase I prior to synthesizing cDNA using the on-column DNase I digestion, as recommended by the manufacturer (Qiagen). The absence of genomic DNA contamination was subsequently confirmed by the lack of PCR amplification of RNA samples with primers designed for the $P$. striiformis $\mathrm{f}$. sp. tritici PSTEF1 gene and P. graminis f. sp. tritici PGTActin gene. First-strand cDNA was synthesized using the iScript cDNA synthesis kit (Bio-Rad, Hercules, CA, U.S.A.) following the manufacturer's instructions.

\section{qRT-PCR and estimations of gene silencing.}

To analyze expression of the targeted genes for silencing, qRT-PCR was carried out using PSTEF1 to normalize RNA amounts for $P$. striiformis $\mathrm{f}$. sp. tritici genes assays (Yin et al. 2009), PST58H22a ( $\beta$-tubulin) was used to normalize RNA amounts for PSTEF1 gene assays, and PGTActin was used for PGTEPSPS gene assays (Broeker et al. 2006). The Pfaffl method was used for relative quantification (Pfaffl 2001) of expression between developmental stages or expression between putative silenced plants and control plants. qRT-PCR was performed using the Bio-Rad iQ5 Real-Time PCR system. Specific primers for each gene were selected from regions outside of those used in RNAi target regions and were designed using primer design software (Table 4). RT-PCR was conducted in $20-\mu l$ volumes using the SsoFast Eva Green kit (Bio-Rad). 
PCR conditions used were $95^{\circ} \mathrm{C}$ for $2 \mathrm{~min}$; followed by $45 \mathrm{cy}$ cles of $95^{\circ} \mathrm{C}$ for $20 \mathrm{~s}, 58^{\circ} \mathrm{C}$ for $30 \mathrm{~s}$, and $72^{\circ} \mathrm{C}$ for $30 \mathrm{~s}$; followed by a melting curve program. The dissociation program was $95^{\circ} \mathrm{C}$ for $1 \mathrm{~min}$ and $55^{\circ} \mathrm{C}$ for $10 \mathrm{~s}$ followed by a slow ramp from 55 to $95^{\circ} \mathrm{C}$. Each experiment included six or more biological replications for each gene and six control seedlings with two technical replicates performed on every sample. Leaf tissue was harvested before rust symptoms (sporulation) were apparent and leaf tissue harvested from some seedlings did not have adequate levels of infection to provide sufficient fungal RNA for silencing estimates; fewer than six biological replications were obtained in these experiments. Gene expression assays for different developmental stages were as described previously (Yin et al. 2009).

To evaluate silencing, the ratios of expression of each putative silenced seedling were compared with each of the control seedlings in each experiment, typically giving six estimates of silencing for each seedling. If no gene silencing was observed for a given seedling infected with a silencing construct, the expected ratio of gene expression in that seedling to the any of the control seedlings would be to equal 1.0. A t-test was then conducted to ask "are the ratios of gene expression in the putative silenced seedling compared with each of the control seedlings different than 1.0?"

Analysis of the relationship between the extent of virus symptoms and the extent of rust sporulation was calculated using PROC GLM in SAS (version 9.1; SAS Institute, Cary, NC, U.S.A.).

\section{ACKNOWLEDGMENTS}

This work was supported in part by National Institute of Food and Agriculture Grant No. 2010-65108-20568. We thank X. Chen for advice concerning wheat and barley cultivars, Puccinia races, and a critical reading of the manuscript; A. Wan for help in scoring rust diseases; and K. Gill and J. Mutti for BSMV vectors and advice on VIGS assays.

\section{LITERATURE CITED}

Baulcombe, D.C. 2004. RNA silencing in plants. Nature 431:356-363.

Baum, J. A., Bogaert, T., Clinton, W., Heck, G. R., Feldmann, P., Ilagan, O., Johnson, S., Plaetinck, G., Munyikwa, T., Pleau, M., Vaughn, T., and Roberts, J. 2007. Control of coleopteran insect pests through RNA interference. Nat. Biotechnol. 25:1322-1326.

Becker, A., and Lange, M. 2009. VIGS-genomics goes functional. Trends Plant Sci. 15:1-4.

Broeker, K., Bernard, F., and Moerschbacher, B. M. 2006. An EST library from Puccinia graminis f. sp. tritici reveals genes potentially involved in fungal differentiation. FEMS (Fed. Eur. Microbiol. Soc.) Microbiol. Lett. 256:273-281.

Brueggeman, R., Druka, A., Nirmala, J., Cavileer, T., Drader, T., Rostoks, N., Mirlohi, A., Bennypaul, H., Gill, U., Kudrna, D., Whitelaw, C., Kilian, A., Han, F., Sun, Y., Gill, K., Steffenson, B., and Kleinhofs, A. 2008. The stem rust resistance gene Rpg5 encodes a protein with nucleotide-binding-site, leucine-rich, and protein kinase domains. Proc. Natl. Acad. Sci. U.S.A. 105:14970-14975.

Chen, X. M., and Line, R. F. 1992. Inheritance of stripe rust resistance in wheat cultivars used to differentiate races of Puccinia striiformis in North America. Phytopathology 82:633-637.

Cloutier, S., McCallum, B. D., Loutre, C., Banks, T. W., Wicker, T., Feuillet, C., Keller, B., and Jordan, M. C. 2007. Leaf rust resistance gene $L r 1$, isolated from bread wheat (Triticum aestivum L.) is a member of the large psr567 gene family. Plant Mol. Biol. 65:93-106.

Feng, P. C., Baley, G. J., Clinton, W. P., Bunkers, G. J., Alibhai, M. F., Paulitz, T. C., and Kidwell, K. K. 2005. Glyphosate inhibits rust diseases in glyphosate-resistant wheat and soybean. Proc. Natl. Acad. Sci. U.S.A. 102:17290-17295.

Frizzi, A., and Huang, S. 2010. Tapping the silencing pathways for plant biotechnology. Plant Biotechnol. J. 8:655-677.

Hannon, G. J. 2002. RNA interference. Nature 418:244-251.

Hein, I., Barciszewska-Pacak, M., Hrubikova, K., Williamson, S., Dinesen, M., Soenderby, I. E., Sundar, S., Jarmolowski, A., Shirasu, K., and Lacomme, C. 2005. Virus-induced gene silencing-based functional charac- terization of genes associated with powdery mildew resistance in barley. Plant Physiol. 138:2155-2164.

Holzberg, S., Brosio, P., Gross, C., and Pogue, G.P. 2002. Barley stripe mosaic virus-induced gene silencing in a monocot plant. Plant $\mathrm{J}$. 30:315-327.

Horvath, H., Rostoks, N., Brueggeman, R., Steffenson, B., von Wettstein, D., and Kleinhofs, A. 2003. Genetically engineered stem rust resistance in barley using the Rpgl gene. Proc. Natl. Acad. Sci. U.S.A. 100:364369.

Huang, G., Allen, R., Davis, E. L. Baum, T. J., and Hussey, R. S. 2006. Engineering broad root-knot resistance in transgenic plants by RNAi silencing of a conserved and essential root-knot nematode parasitism gene. Proc. Natl. Acad. Sci. U.S.A. 103:14302-14306.

Huvenne, H., and Smagghe, G. 2010. Mechanisms of dsRNA uptake in insects and potential of RNAi for pest control: A review. J. Insect Physiol. $56: 227-235$.

Kumagai, M. H., Donson, J., Della-Cioppa, G., Harvey, D., Hanley, K., and Grill, L. K. 1995. Cytoplasmic inhibition of carotenoid biosynthesis with virus-derived RNA. Proc. Natl. Acad. Sci. U.S.A. 92:1679-1683.

Line, R. F., and Qayoum, A. 1992. Virulence, aggressiveness, evolution, and distribution of races of Puccinia striiformis (the cause of stripe rust of wheat) in North America, 1968-87. In: Tech. Bull. No. 1788. United States Department of Agriculture, Agricultural Research Service, Washington, D.C.

Mendgen, K., and Hahn, M. 2002. Plant infection and the establishment of fungal biotrophy. Trends Plant Sci. 7:352-356.

Nakayashiki, H. 2005. RNA silencing in fungi: Mechanisms and applications. FEBS (Fed. Eur. Biochem. Soc.) Lett. 579:5950-5957.

Nakayashiki, H., and Nguyen, Q. B. 2008. RNA interference: Roles in fungal biology. Curr. Opin. Microbiol. 11:494-502.

Nakayashiki, H., Kadotani, N., and Mayama, S. 2006. Evolution and diversification of RNA silencing proteins in fungi. J. Mol. Evol. 63:127135.

Nazari, K., Mafi, M., Yahaoui, A., Singh, R. P., and Park, R. F. 2009. Detection of wheat stem rust (Puccinia graminis f. sp. tritici) race TTKSK (Ug99) in Iran. Plant Dis. 93:317.

Nowara, D., Gay, A., Lacomme, C., Shaw, J., Ridout, C., Douchkov, D., Hensel, G., Kumlehn, J., and Schweizer, P. 2010. HIGS: Host-induced gene silencing in the obligate biotrophic fungal pathogen Blumeria graminis. Plant Cell 22:3130-3141.

Pfaffl, 2001. A new mathematical model for relative quantification in realtime RT-PCR. Nucleic Acids Res. 29:2002-2007.

Pretorius, Z. A., Singh, R. P., Wagoire, W. W., and Payne, T. S. 2000. Detection of virulence to wheat stem resistance gene Sr31 in Puccinia graminis f. sp. tritici in Uganda. Plant Dis. 84:203.

Renner, T., Bragg, J., Driscoll, H. E., Cho, J., Jackson, A. O., and Specht, C. D. 2009. Virus-induced gene silencing in the culinary ginger (Zingiber officinale): An effective mechanism for down-regulating gene expression in tropical monocots. Mol. Plant. 2:1084-1094.

Scofield, S. R., and Nelson, R. S. 2009. Resources for virus-induced gene silencing in the grasses. Plant Physiol. 149:152-157.

Scofield, S. R., Huang, L., Brandt, A. S., and Gill, B. S. 2005. Development of a virus-induced gene-silencing system for hexaploid wheat and its use in functional analysis of the Lr21-mediated leaf rust resistance pathway. Plant Physiol. 138:2165-2173.

Sindhu, A. S., Maier, T. R., Mitchum, M. G., Hussey, R. S., Davis, E. L., and Baum, T. J. 2009. Effective and specific in planta RNAi in cyst nematodes: Expression interference of four parasitism genes reduces parasitic success. J. Exp. Bot. 60:315-324.

Singh, R. P., Hodson, D. P., Huerta-Espino, J., Jin, U., Njau, P., Wanyera, R., Herrera-Foessel, S. A., and Ward, R. W. 2008. Will stem rust destroy the world's wheat crop? Adv. Agron. 98:271-309.

Stakman, E. C., Stewart, D. M., and Loegering, W. Q. 1962. Identification of physiologic races of Puccinia graminis var. tritici. Agric. Res. Serv. E 617. U. S. Dep. Agric. Washington, DC.

Szabo, L. J., and Bushnell, W. R. 2001. Hidden robbers: The role of fungal haustoria in parasitism of plants. Proc. Natl. Acad. Sci. U.S.A. 98:76547655 .

Tinoco, M. L. P., Dias, B., Dall'Astta, R. C., Pamphile, J. A., and Aragão, F. J. L. 2010. In vivo trans-specific gene silencing in fungal cells by in planta expression of a double-stranded RNA. BMC Biol. 31:27.

Tomilov, A. A., Tomilova, N. B., Wroblewski, T., Michelmore, R., and Yoder, J. I. 2008. Trans-specific gene silencing between host and parasitic plants. Plant J. 56:389-397.

Voegele, R. T., Struck, C., Hahn, M., and Mendgen, K. 2001. The role of haustoria in sugar supply during infection of broad bean by the rust fungus Uromyces fabae. Proc. Natl. Acad. Sci. U.S.A. 98:8133-8138.

Wang, X., Cao, A., Yu, C., Wang, D., Wang, X., and Chen, P. 2009. Establishment of an effective virus induced gene silencing system with BSMV in Haynaldia villosa. Mol. Biol. Rep. 37:967-972. 
Wanyera, R., Kinyua, M. G., Jin, Y., and Singh, R. P. 2006. The spread of stem rust caused by Puccinia graminis f. sp. tritici, with virulence on Sr31 in wheat in Eastern Africa. Plant Dis. 90:113.

Yadav, B. C., Veluthambi, K., and Subramaniam, K. 2006. Host-generated double stranded RNA induces RNAi in plant-parasitic nematodes and protects the host from infection. Mol. Biochem. Parasitol. 148:219-222.

Yin, C., Chen, X., Wang, X., Han Q. M., Kang, Z., and Hulbert, S. H. 2009. Generation and analysis of expression sequence tags from haustoria of the wheat stripe rust fungus Puccinia striiformis f. sp. tritici. BMC Genomics 10:626.
Zhou, H., Li, S., Deng, Z., Wang, X., Chen, T., Zhang, J., Chen, S., Ling, H., Zhang, A., Wang, D., and Zhang, X. 2007. Molecular analysis of three new receptor-like kinase genes from hexaploid wheat and evidence for their participation in the wheat hypersensitive response to stripe rust fungus infection. Plant J. 52:420-434.

\section{AUTHOR-RECOMMENDED INTERNET RESOURCE}

Integrated DNA Technologies PrimerQuest webpage: www.idtdna.com/Scitools/Applications/Primerquest 